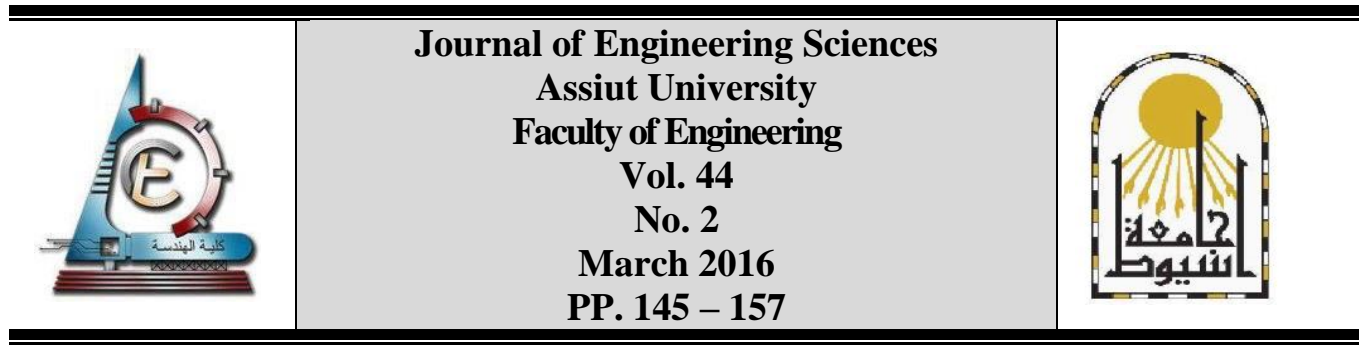

\title{
DESIGN AND IMPLEMENTATION OF CONTROL CIRCUIT FOR A STAND-ALONE PHOTOVOLTAIC LED ROAD LIGHTING SYSTEM
}

\author{
Hammad Abo-Zied Mohammed * and Hamdy A. Ziedan \\ Electrical Eng. Depart. Faculty of Engineering, Assiut University, 71518 Assiut, Egypt.
}

Received 20 February 2016; Accepted 1 March 2016

\begin{abstract}
This paper is aimed at designing and implementing of control circuits for a stand-alone photovoltaic (PV) LED road lighting system. The main parts of the control circuit are A DC/DC converter and microprocessor control circuit. Control circuit for this system is adjust for Maximum Power Point Tracking (MPPT), which makes the road lighting system operated effectively and adjusts battery charging process. Also, control circuit function is considered to automatically switch lights $\mathrm{ON}$ at sunset. The simulation study is done by using the PSIM and Simulation of MATLAB software to achieve good design. Experimental work has been done in the Laboratory of Renewable Energy at Assiut University, Egypt. Experimental results verify the feasibility of this design.
\end{abstract}

Keywords: Photovoltaic, Stand-alone system, optimal control circuit, LED road lighting system, control of battery charging.

\section{Introduction}

Renewable energy is generated from natural resources like sun and wind. So, it is very clean energy, freely infinitely available and of high reliability. It is a very important power source for many applications as remote areas. Initial cost of solar Energy is high; but running cost is low. Also, the maintenance cost is low. Solar energy can be obtained from the sun. It is in the form of solar radiation. Amount of energy production depends on Photovoltaic characteristics and the amount of solar irradiation. Solar irradiance effects on the value of solar module current [1-3]. Photovoltaic lighting systems are usually standalone systems as shown in Fig.1, [4, 5]. Design of the PV system consists of three steps, capacity design, electrical circuit design and control circuits design. Capacity design is used to determine the number of solar panel arrays, battery arrays and matching loads. The second step is used to design a suitable electrical circuit to meet the requirement, $[6,7]$. The first and the second steps were explained in detail by the authors in reference [8].

The power output of the photovoltaic system can be maximizing by a high efficiency converter and low cost DC/DC converter. With a voltage feedback signal is used to control the

\footnotetext{
* Corresponding author.

E- mail address: yassmen1@yahoo.com
} 
terminal voltage of the photovoltaic system at optimal values in various solar radiation conditions (MPPT). The operation performance of the photovoltaic lighting system depends on the controller circuit. LED light consumes very less power. Also, its life time is high. So, in this work, LED is used as lighting bulb. This paper is aimed at designing and implementing of optimal control circuit of stand-alone PV lighting system for highways and car parking lighting.

\section{Design of control circuits}

Control circuits of PV system consist of two main parts. The first part is a maximum power point tracking (MPPT) control circuit. The second part is a charging and discharging batteries control circuit. The block diagram of PV lighting system is shown in Fig. 2, [9, 10, 11].

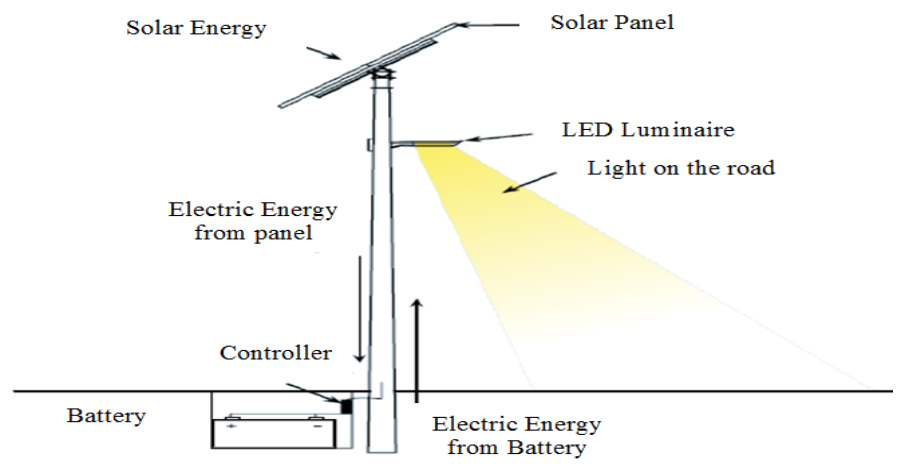

Fig. 1. Stand-alone PV system components of Lighting System.

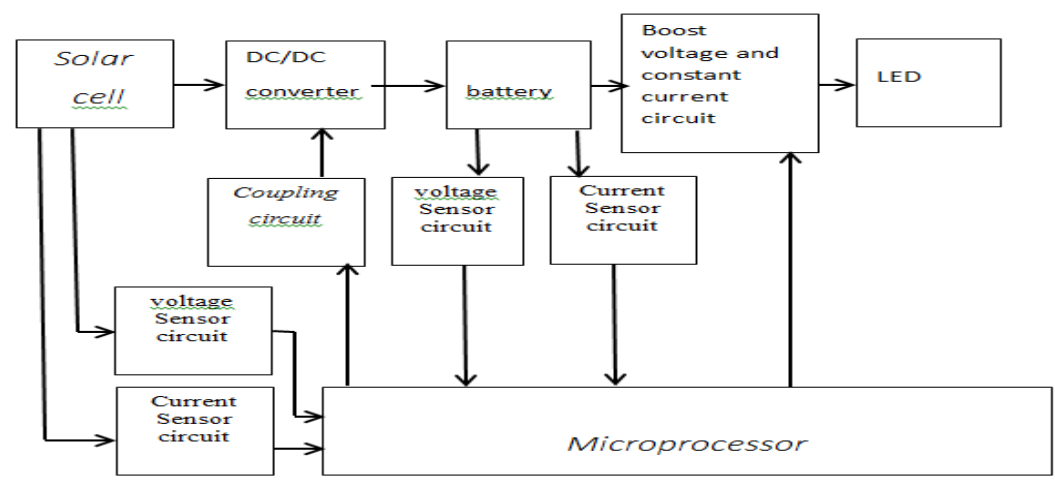

Fig. 2. Block diagram of PV Lighting System.

\subsection{Design of MPPT control circuit}

MPPT control circuit is a fully electronic circuit. It is including a microprocessor and DC/DC step down converter. The converter is used for battery charging of PV system. Microprocessor is tried to maximize power input from solar panel. It controlled step down voltage ratio to keep solar panel operates at its maximum power point [12-16]. The MPPT control circuit of PV system contains of the following main parts:

\section{A. Current sensors}

The electrical currents are detected by using current sensors. The current sensor generates analog or digital signals proportional to the value of the electrical current. This signal can be 
used for control purpose as shown in Fig.3. In this work, the generated signal from sensor is analog voltage. Current is measured by taking a signal from the circuit using a very small series resistance. Resistance $R_{l}$ of $0.05 \Omega$ with rated power up to $6 \mathrm{~W}$ is used as shown in Fig.3. a differential amplifier circuit is used as a compensator. The compensator gain is 10 . This compensator is used to avoid power loss and compensate voltage drop in the circuit.

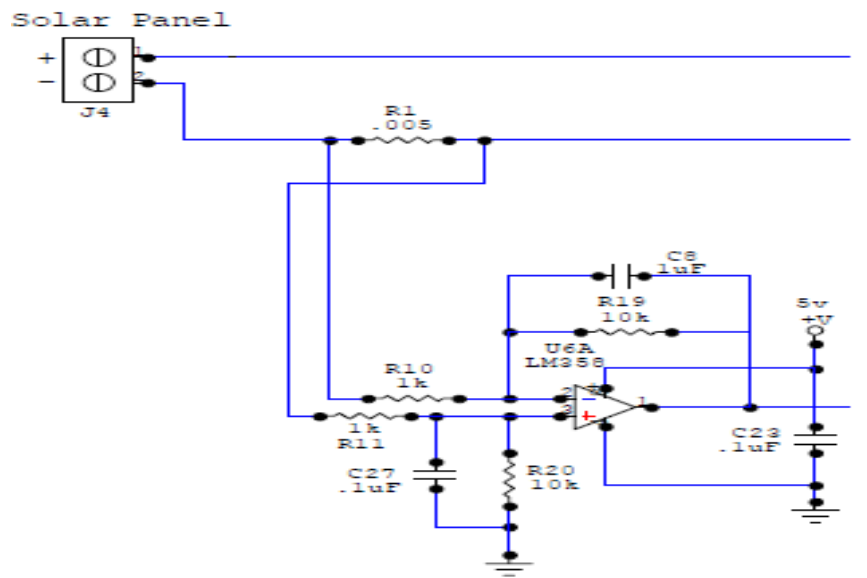

Fig. 3. Current sensor circuit.

\section{B. Voltage sensor}

Voltage can be sensed by voltage divider circuit as shown in Fig.4. This is simple linear circuit. The output voltage $\left(V_{\text {out }}\right)$ expressed as a fraction of input voltage $\left(V_{\text {in }}\right)$ as expressed by Eqn. 1 .

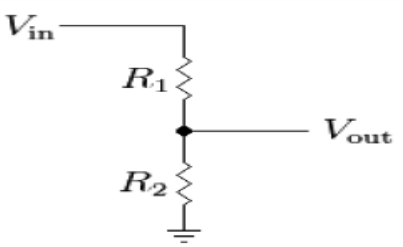

Fig. 4. Voltage sensor circuit.

$$
\begin{aligned}
& V_{\text {out }}=\frac{R_{2}}{R_{1}+R_{2}} \cdot V_{\text {in }} \\
& V_{\text {out }}=D \cdot V_{\text {in }}
\end{aligned}
$$

where $\mathrm{D}$ is duty cycle.

\section{Buck converter}

Buck converter is step-down DC to DC converter based on current in inductor. The inductor current is controlled by switches. MOSFET transistor is used as switch in buck converter circuit as shown in Fig.5. 


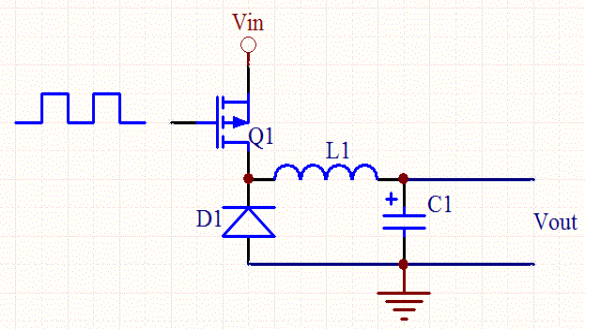

Fig. 5. Buck converter.

\section{Microprocessor control}

The microprocessor control circuit and the DC/DC converter is shown in Fig. 6. [15, 16]. In this circuit, the DC/DC converter is controlled by a microprocessor (PIC16F877A). The microprocessor is clocked at $20 \mathrm{MHz}$ by the crystal XTAL1. The microprocessor output of PWM is used to control duty cycle of DC/DC converter which sets its voltage conversion ratio. The PWM frequency can be sets to $100 \mathrm{KHz}$ by using PIC software. Also, the PWM duty cycle can be controlled by using PIC software. This control to optimize solar panels output power [17]. The microprocessor output is used to controlling the MOSFET driver (2004A). The microprocessor calculates the power generated from the solar panels through A/D converter as shown in Fig.6.

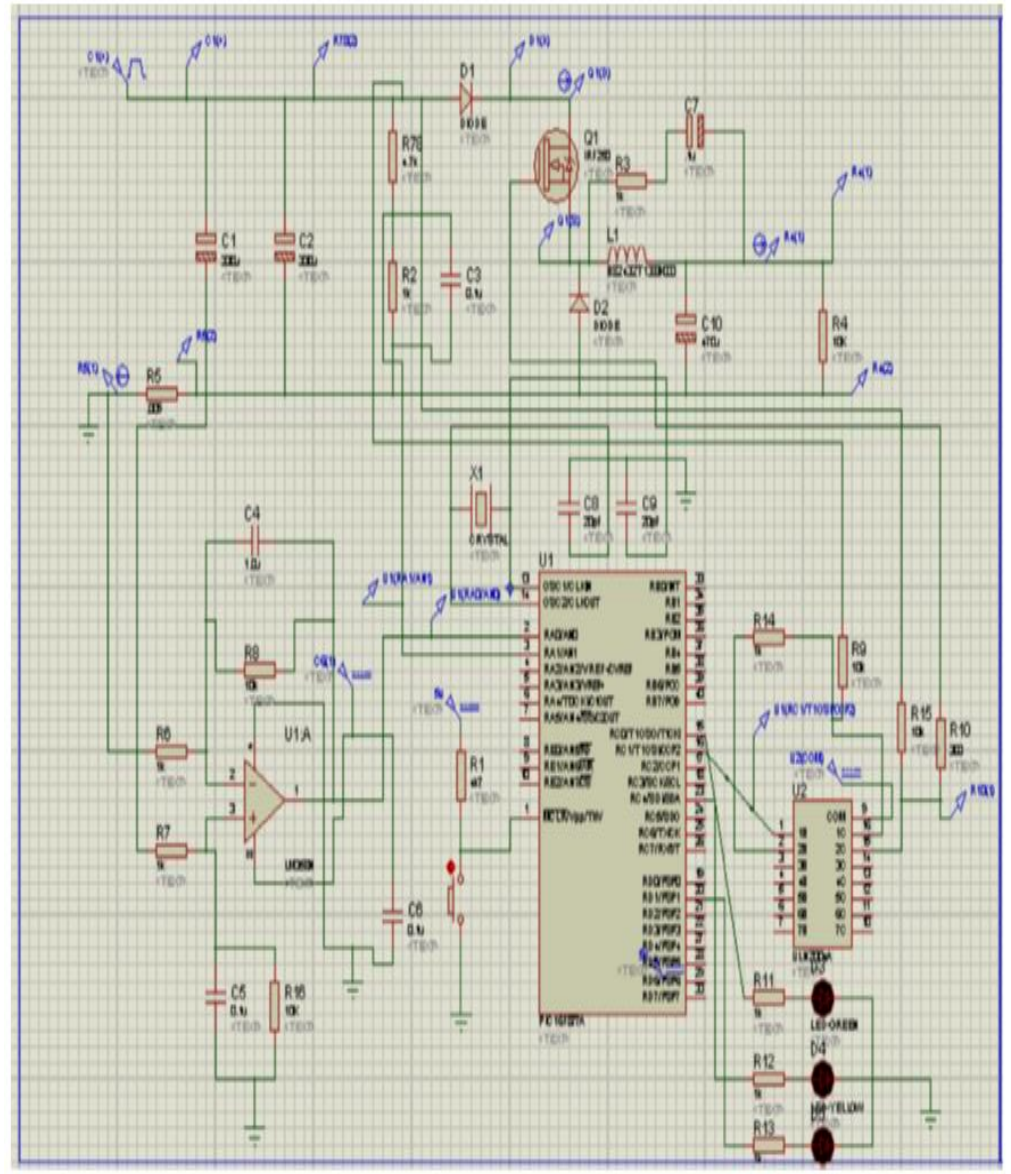

Fig. 6. The microprocessor control circuit and the DC/DC converter. 


\section{E. Circuit description and operation}

The DC/DC converter is a synchronous MOSFET $\left(\mathrm{Q}_{1}\right)$ with energy storage devices as shown in Fig.6. In this figure, the storage devices are inductor $\left(\mathrm{L}_{1}\right)$ and capacitors $\left(\mathrm{C}_{1}, \mathrm{C}_{2}\right.$ and $\mathrm{C}_{10}$ ). The inductor value is $33 \mathrm{uH}$ and inductor current $11 \mathrm{~A}$ for this work. Both high side and low side MOSFETs are IRFf250 N-fets. The turn on resistance $\left(\mathrm{R}_{\mathrm{ds}}\right)$ is low. So, $\mathrm{N}$-fets were chosen to reduce resistance losses in DC/DC converter. When low side MOSFET is turning on, the circulating current will be flow through a fast recovery diode $\left(\mathrm{D}_{2}\right)$. Electrical noise which generated by switching of inductor can be reduced by snubber circuit $\left(\mathrm{C}_{7}, \mathrm{R}_{3}\right)$. During battery charging, diode $\left(\mathrm{D}_{1}\right)$ is used to turn off the system. The MOSFET transistor $\left(\mathrm{Q}_{1}\right)$ is turned off at night. Also, microprocessor will shut off when there is no longer any solar power to run it. Diode $\left(\mathrm{D}_{1}\right)$ is used to block reverse current flow. All the above elements of the DC/DC converter $\left(\mathrm{Q}_{1}, \mathrm{~L}_{1}, \mathrm{C}_{1}, \mathrm{C}_{2}, \mathrm{C}_{10}, \mathrm{C}_{7}, \mathrm{R}_{3}, \mathrm{D}_{1}, \mathrm{D}_{2}, \mathrm{R}_{\mathrm{ds}}\right)$ are shown in Fig.6. The MOSFET gate driver (2004A) drives high and low side MOSFETs using PWM signal from microprocessor. Equivalent circuit of the MOSFET gate driver (IC2004A) is shown in Fig.7.

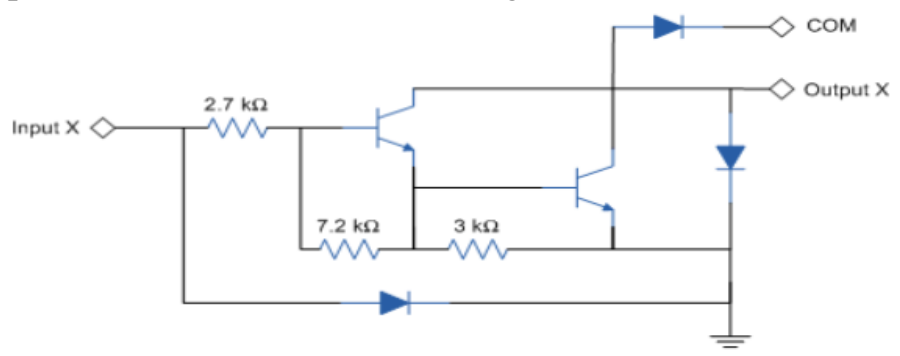

Fig. 7 Equivalent circuit of the gate driver IC2004A.

The microprocessor input voltage is dropped to $5 \mathrm{~V}$ by using voltage divider $\left(\mathrm{R}_{2}, \mathrm{R}_{3}\right)$. The current sensor is achieved by a resistor $\left(\mathrm{R}_{5}\right)$. Communicate and interface code into PIC and run simple debugging commands can be done by using program MPLAB without removing processor. PIC is built in serial port that used the data from Peak Power Tracker (PPT). So, it can be placed externally.

The DC/DC converter design with fixed conversion ratio is very simple, when the maximum power point of solar panel is fixed. In this case, the converter converts maximum power point voltage down to battery voltage level. However, the maximum power point of solar panels is not fixed. The maximum power point depends on the amount of irradiation and temperature of the solar panels. So, the converter design is not simple. Microprocessor takes care of this by measuring input power from solar panel and changing the conversion ratio to keep solar panel at its MPP as shown in Fig.6.

The DC/DC converter converts high input voltage into low output voltage with very small power losses. So, output power is equal to input power. Due to the input power is equal to the output power and the input voltage is higher than the output voltage, the output current is higher than the input current. This is a synchronous switching converter, which it has low and high sides MOSFET switch. This is more efficient than a converter with just a high side switch. This converter has less resistive losses during the switches. However, this causes problems with driving high side MOSFET. The MOSFET gate to source voltage $\left(\mathrm{V}_{\mathrm{gs}}\right)$ must be greater than $8 \mathrm{~V}$ to fully turn on. The high side switch in DC/DC converter has its source pin tied to input voltage, so we have to generate a gate drive voltage of at least $8 \mathrm{~V}$ higher than the input voltage. This is taken care of by bootstrap capacitor 
connected to MOSFET driver (2004A). When low side switch is on, bootstrap capacitor is charged to the input voltage. Then, when high side switch is on, capacitor adds voltage to input voltage. So, double input voltage now drives high side switch. High side switch is turned on full time to connect solar panel to battery directly. Microprocessor, (PIC16F877A), controls the conversion ratio of DC/DC converter. PIC generates a pulse width modulation signal at $100 \mathrm{kHz}$ with its internal PWM circuit. Duty cycle of PWM signal sets ratio of on time for high side versus low side of MOSFET switch. On time ratio of switches sets the conversion ratio of input to output voltage of DC/DC converter.

The microprocessor sets conversion ratio of DC/DC converter to allow solar panels to operate at their MPP. Iterative algorithm has been used by microprocessor to maximize input power of solar panels. Input power from solar panel is calculated by measuring voltage and current with PIC's A/D inputs and multiplying internally to get power. Microprocessor transmits out serial port all values it has measured and calculated (volt, current and power) once a second to be logged by an external computer. Solar panel input power are measured and compared with solar panel power at MPP to get the gain or boost of PPT [17].

\subsection{Design of control circuit of battery charger}

Function of solar charge controller is to regulate power flowing from solar panels to rechargeable batteries. It consists of one potentiometer for float voltage adjustment, an equalize function for periodic overcharging, and automatic temperature compensation for better battery charging over a wide range of temperatures. This circuit is able to handle reverse polarity connection of both battery and photovoltaic panel [6-13]. Battery Charger simulation circuit is shown in Fig.8, [13 - 14].

\section{Experimental technique}

Experimental work has made in Renewable Energy Laboratory, Electrical Engineering Department, Assiut University, Egypt. Characteristics of PV Module are $83 \mathrm{~W}$ with a maximum open circuit voltage $\left(V_{o c}\right)$ of $19.7 \mathrm{~V}$, maximum short circuit current $\left(I_{s c}\right)$ of 5.78 A, maximum power voltage $\left(V_{\text {rate }}\right)$ of $15 \mathrm{~V}$ and maximum power current $\left(I_{\text {rate }}\right)$ of $5 \mathrm{~A}$. These characteristics are obtained experimentally during the day time as shown in Fig.9.

Conventional controller simply connects module and battery. Therefore, if module will operate at $12 \mathrm{~V}$, conventional controller artificially will limit power production to $63 \mathrm{~W}$. In this work, MPPT system operates module at $15 \mathrm{~V}$ to extract full power at $83 \mathrm{~W}$.

\section{Implementation results and discussion}

\subsection{Implementation of MPPT control circuit}

Fig.10 shows the connection diagram of MPPT circuit which was implemented in the laboratory. Switching signal with frequency of $100 \mathrm{KHz}$ was generated by PIC as shown in Fig.11.

\subsection{Implementation of control circuit of battery charger}

Charging circuit is connected between PV module and battery. The connection diagram of the battery charger is shown in Fig. 12. 
Hammad Abo-Zied Mohammed and Hamdy A. Ziedan, Design and implementation of control .......

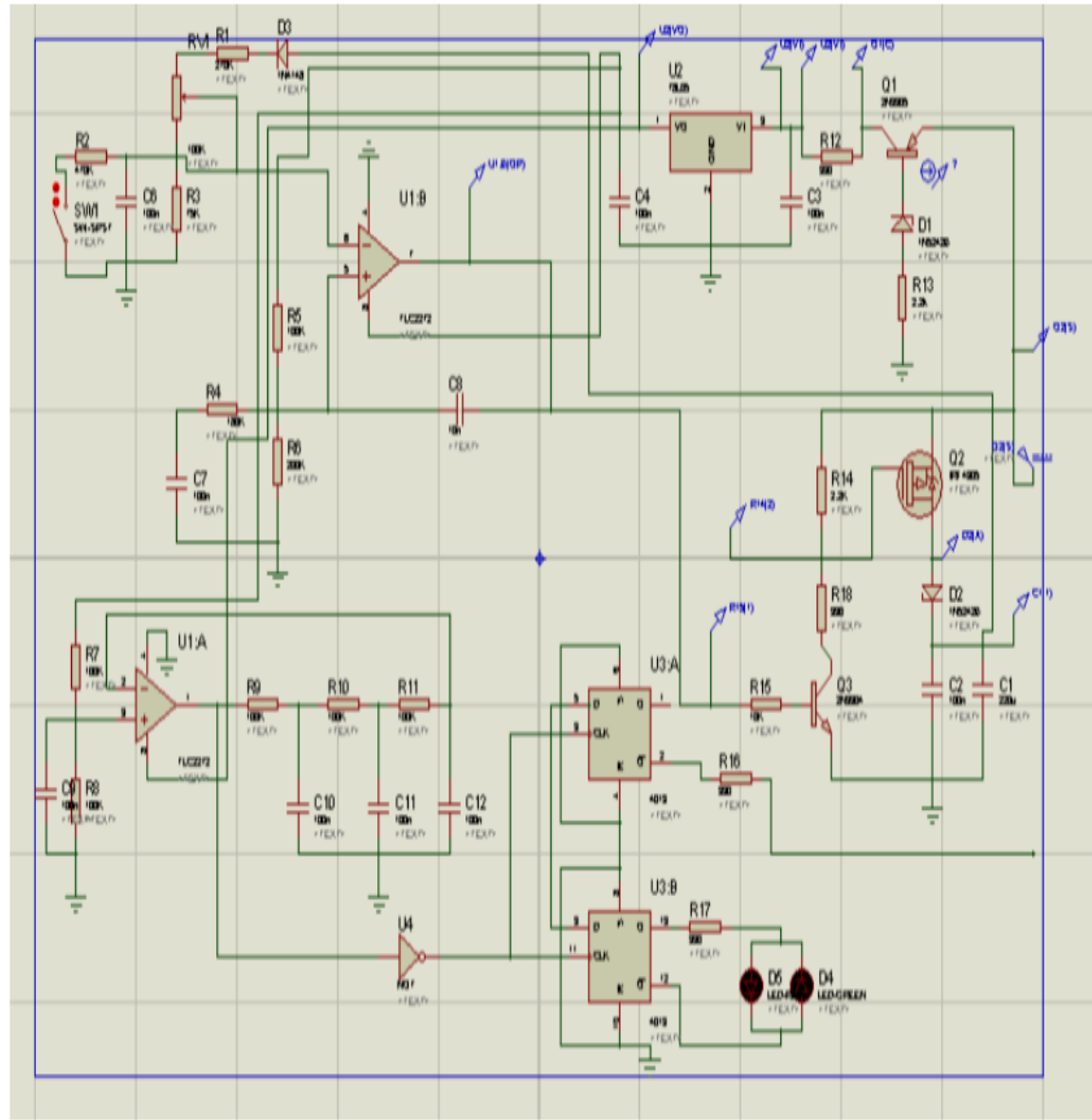

Fig. 8. Simulation circuit for Battery Charger.
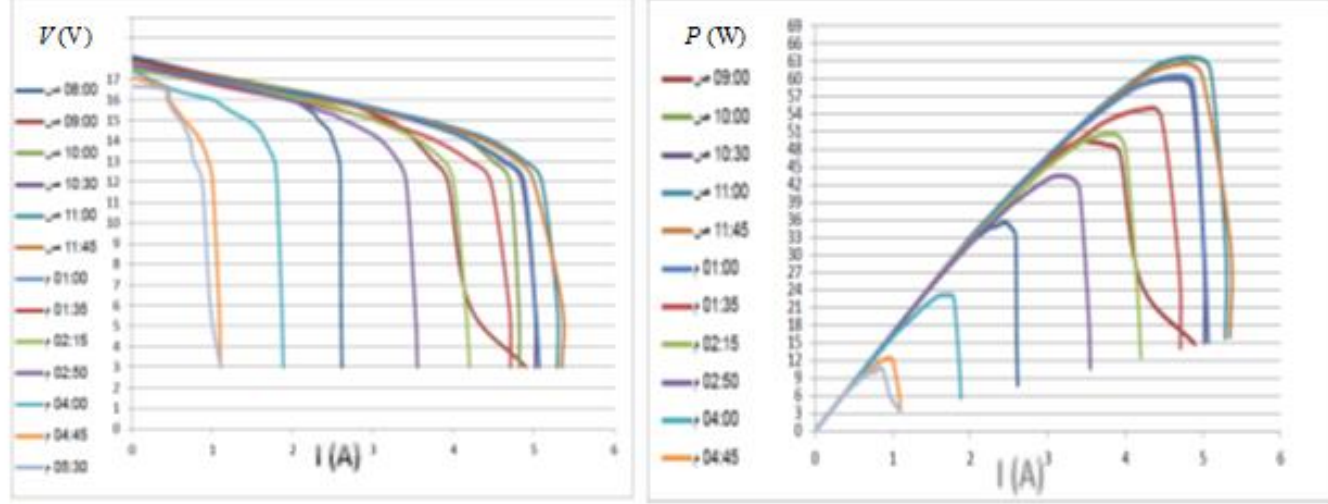

Fig. 9. PV Module real characteristics as obtained experimentally (Assiut University). 


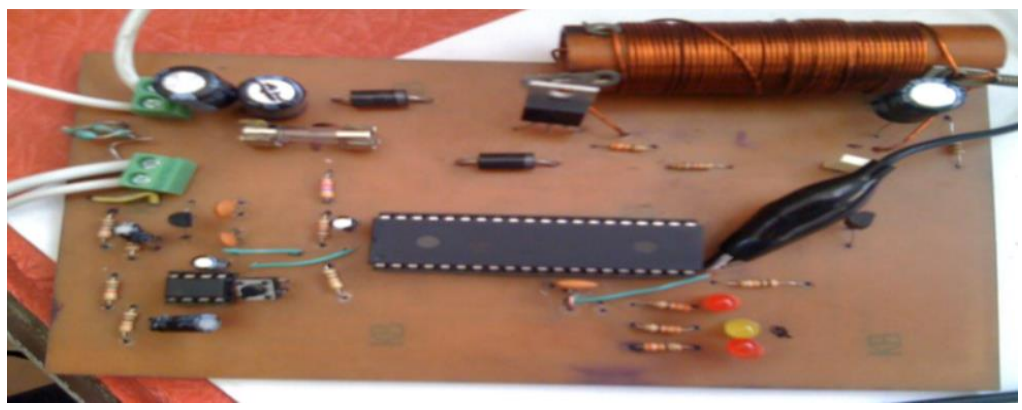

Fig. 10. Connection diagram of MPPT circuit (Assiut University).

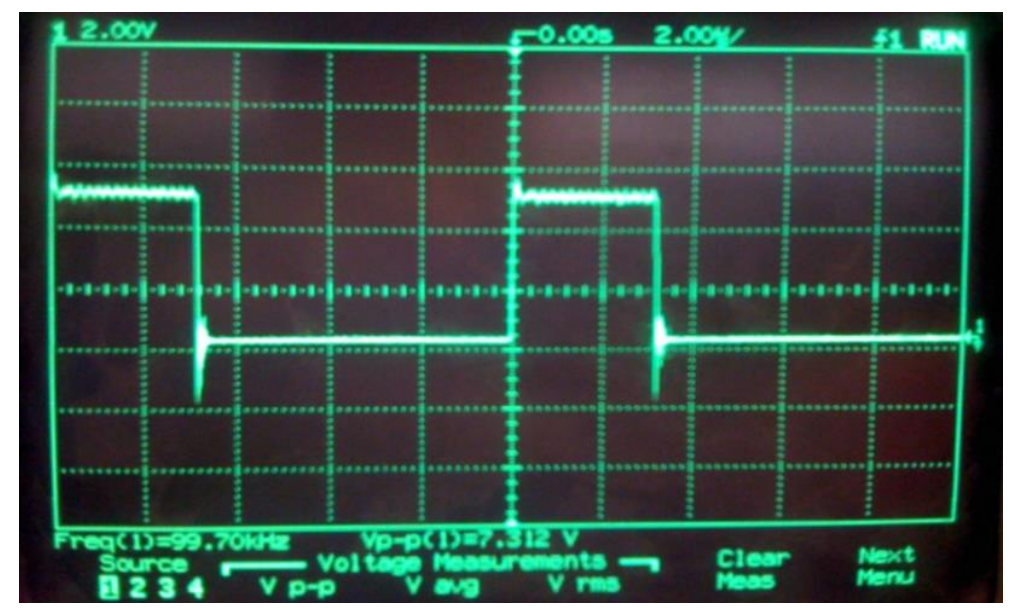

Fig. 11. switching signal with $100 \mathrm{KHz}$ frequency (Assiut University).

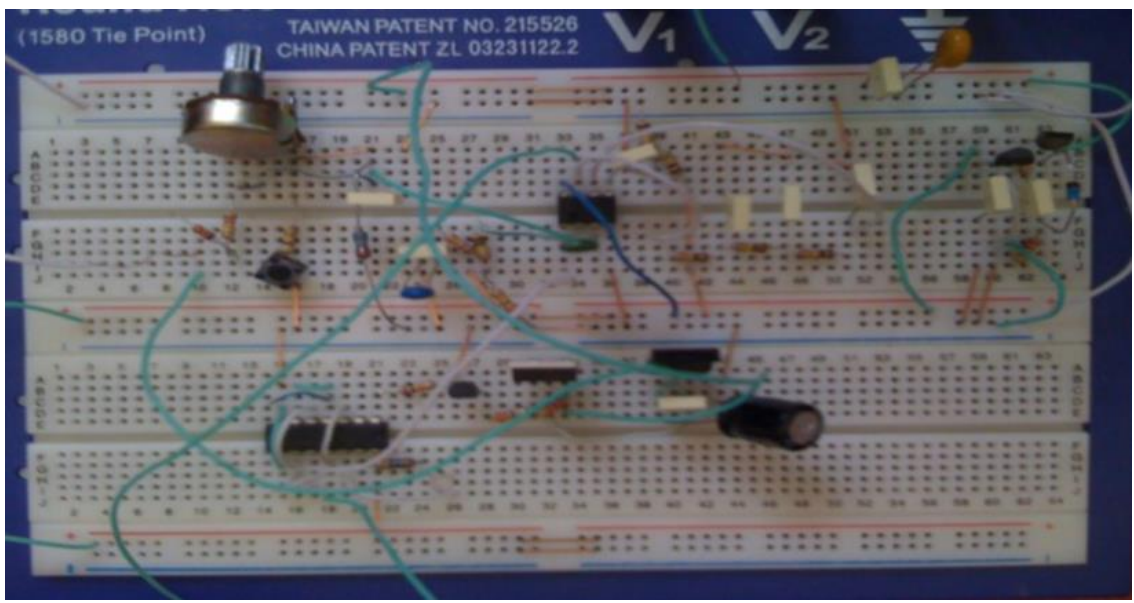

Fig.12. Connection diagram of battery charger (Assiut University).

The charging circuit consists of the following main parts:

\section{A. Voltage regulator}

IC 78105 was used to generate 5 V-DC. Output voltage signal of IC 78105 is shown in Fig.13. This voltage is used for all circuit parts which need DC voltage to operate such as comparator and flip-flop. 


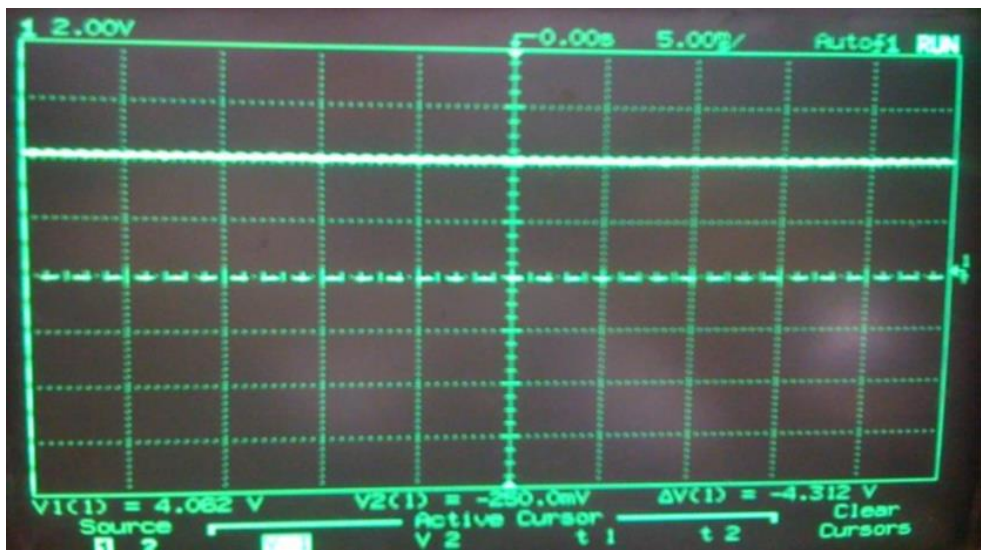

Fig.13 Output voltage signal of IC 78L05 (Assiut University).

\section{B. Clock oscillation}

Comparator IC1b was used to generate a square wave pulses. These pulses were used to trigger clock of flip-flop. Wave frequency was $37 \mathrm{~Hz}$. Square wave pulses, clock oscillation, are shown in Fig. 14.

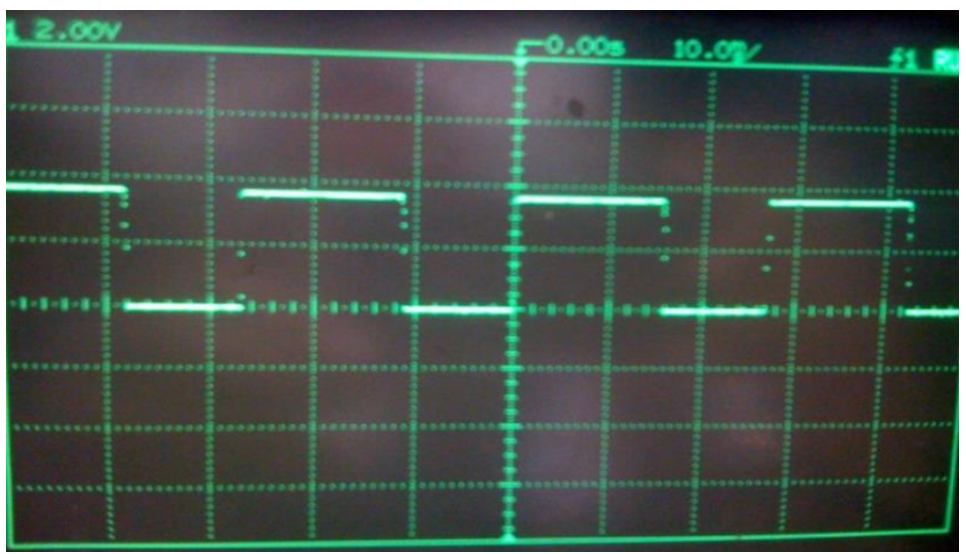

Fig. 14. Square wave pulses, clock oscillation (Assiut University).

\subsection{Charging and discharging states of battery}

There are two different states for operation of battery charging circuit:

\section{A. Charging state}

Comparator IC1a compares battery voltage level with a reference floating voltage. When battery is empty (less than $12 \mathrm{~V}$ ), non-inverting input $(\mathrm{V}+$ ) will be higher than inverting input ( $\mathrm{V}-)$, high gain of op-amp causes output to saturate at the highest positive voltage of $(+5 \mathrm{~V})$ as shown in Fig.15. Output of comparator will make flip-flop operate due to clock pulse as shown in Fig.16. Flip-flop output signal is shown in Fig.17. It will operate transistor Q1 which make IRF4905 operate and connect PV to battery to start charging as shown in Fig.18. When the battery exceeds 12 V. So, IC1a and flip-flop outputs drop to zero and battery charging comes to end. 


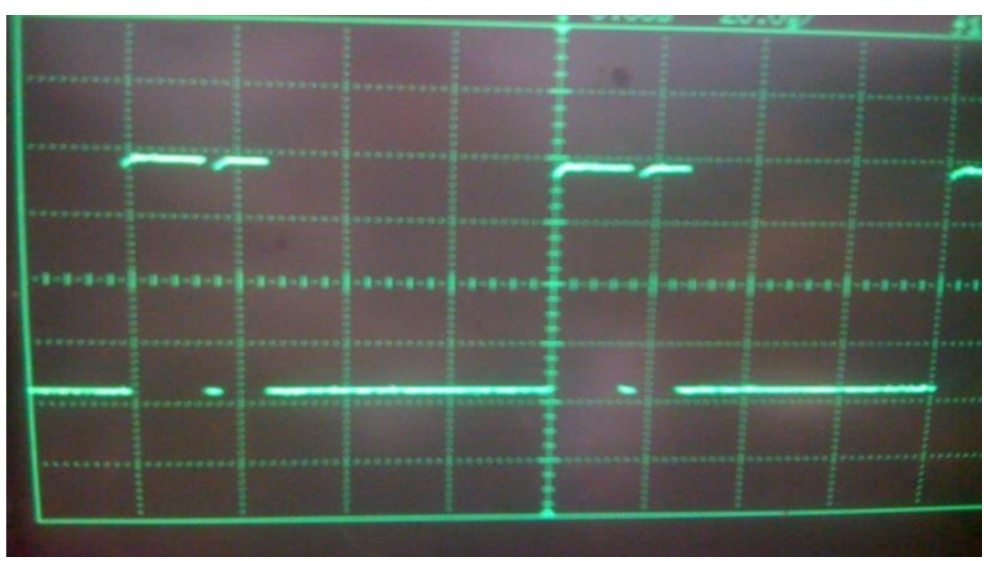

Fig. 15. Output signal of comparator (Assiut University).

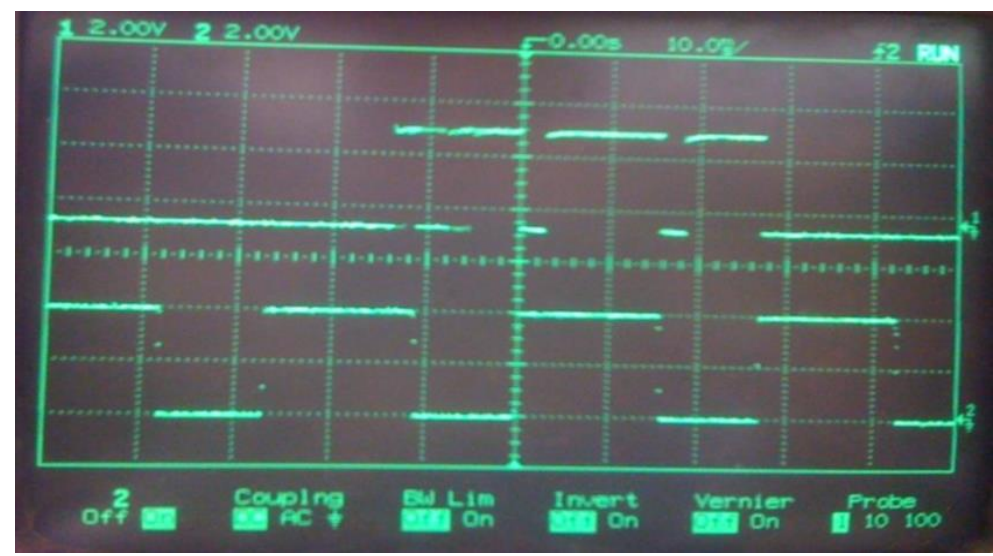

Fig. 16. Comparing of comparator signal with the clock oscillation signal (Assiut University).

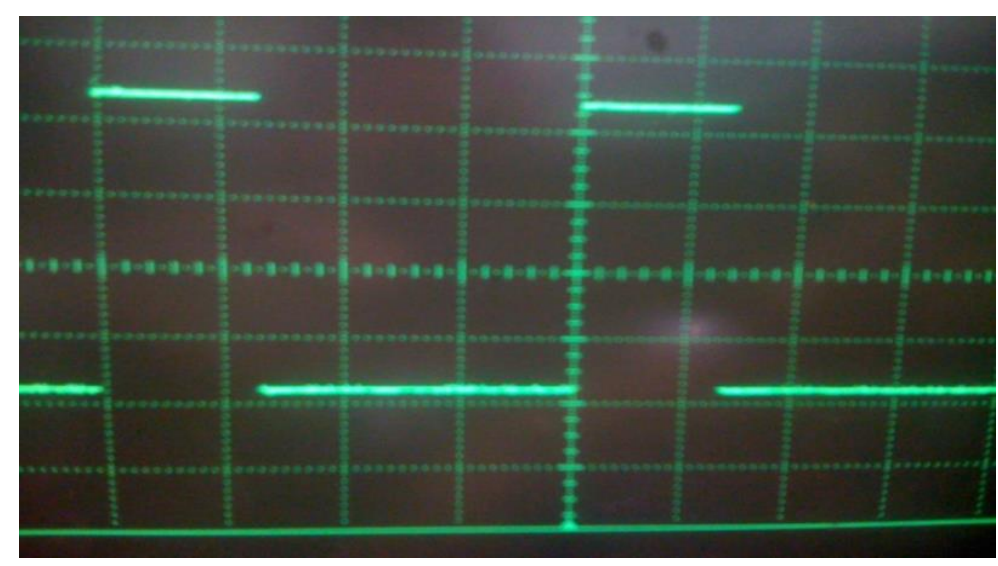

Fig. 17. Output signal of flip-flop (Assiut University).

\section{B. Discharging state}

In discharging state, battery voltage is higher than $12 \mathrm{~V}$. Transistor Q1 will not operate and subsequently IRF4905 will not operate also and the battery continues discharging. 


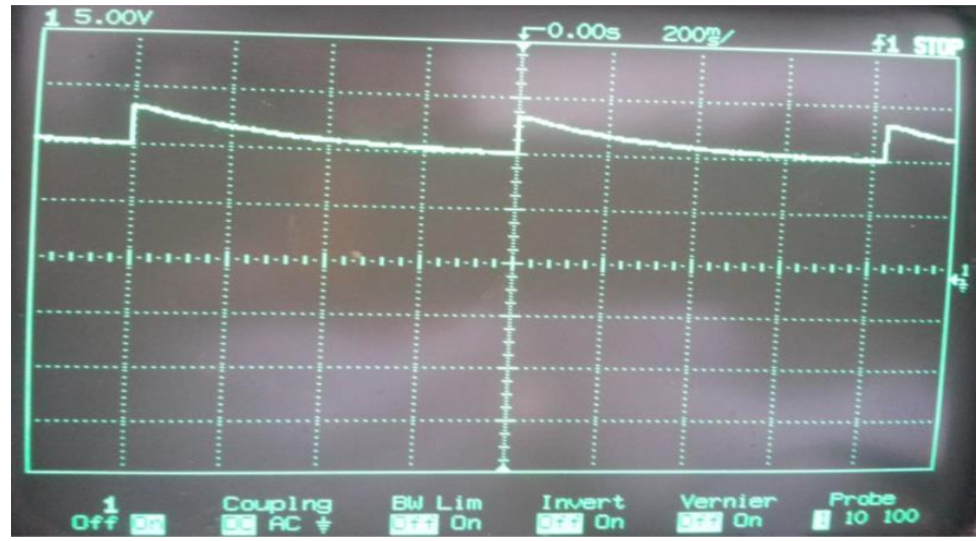

Fig. 18. Battery voltage signal (Assiut University).

\subsection{Voltage on charging state LED}

In charging state, battery voltage is periodically, turning on and off as shown in Fig.19. Period of change depends on battery condition. When it is empty, turning off time will be very small, so change in red light can't be noticed, but when its voltage is float voltage, turning off time increases to exceed the charging time value and LED light is turned to be green.

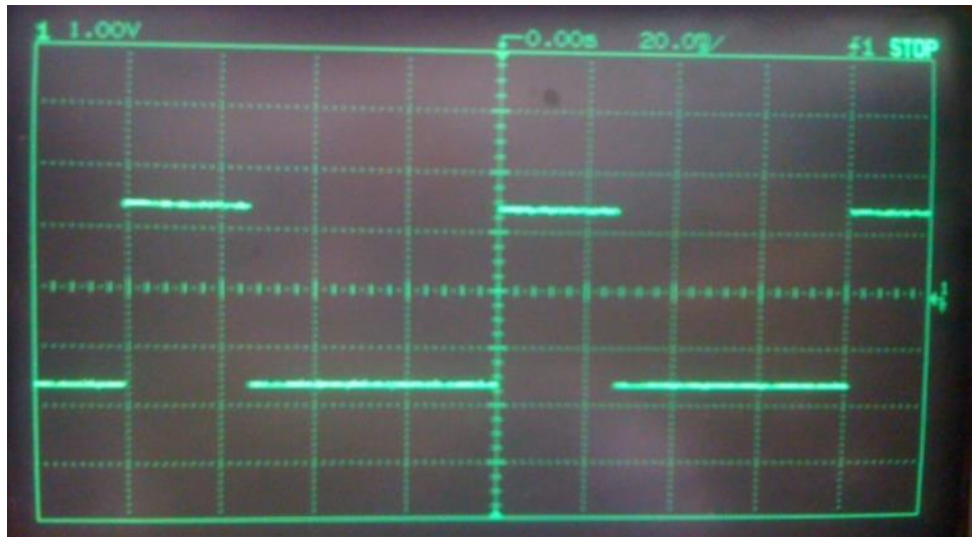

Fig.19. Voltage signal on charging state LED (Assiut University).

\section{Conclusions}

The use of photovoltaic lighting system becomes very attractive. Due to, the Photovoltaic lighting system is high reliability, low maintenance, and low running cost. This paper present a design and implementation of control circuit for a stand-alone photovoltaic LED road lighting. This system is used for highways and car parking lighting. The electrical design requirement as a battery charger circuit is presented in this paper. The control of lighting system includes a circuit for maximum power point tracking of solar irradiation. Therefore, MPPT circuit optimize the power from the PV cell. Also, A DC/DC converter with microprocessor control is developed based on low cost. The PWM technique is used to control duty cycle of DC/DC converter. The proposed system has many advantages. It has less number of components. So, the system is less complex and more economical. The experimental results are provided to verify the applicability of the proposed system. The proposed lighting system is tested and worked satisfactorily. 


\section{Acknowledgment}

The authors would like to thank Prof. Mazen Abdel-Salam of Assiut University, Egypt for his interest and help in this research work.

\section{REFERENCES}

[1] B Parida, S Iniyanb, R. Goicc, "A review of solar photovoltaic technologies", Renewable Sustainable Energy Rev, pp. 1625-1636, 15/3/2011.

[2] Khaled Bataineh, Doraid Dalalah, "Optimal Configuration for Design of Stand-Alone PV System”, Smart Grid and Renewable Energy, scientific research, PP. 139-147, 3, 2012.

[3] M. Villalva, J. Gazoli, and E. Filho, "Comprehensive approach to modeling and simulation of photovoltaic arrays", IEEE Trans. on Power Electronics, Volume 24, pp. 1198-1208. 2009.

[4] S. Harrington and T. Hund, "Photovoltaic lighting system performance", $25^{\text {th }}$ IEEE Photovoltaic Specialists Conference, pp. 1307-1310, Washington DC, USA, 1996.

[5] S. Hiranvardom, "A Comparative analysis of photovoltaic street lighting systems installed in Thailand", $3^{\text {rd }}$ IEEE World Conference on Photovoltaic Energy Conversion, pp. 24782481, Osaka, Japan, May 2003.

[6] D. Srivatsa, B. Preethi, R. Parinitha, G. Sumana and A. Kumar, "Smart Street Lights", TIIEC, Texas Instruments Conference on India Educators, India, pp.103-106, 2013.

[7] W. Yue, S. Changhong, Z. Xianghong and Y. Wei, "Design of new intelligent street light control system", $8^{\text {th }}$ IEEE International Conference on Control and Automation, China, pp. 1423-1427, 2010.

[8] H. Abo-Zied Mohammed and M. Bedda. "Stand-alone photovoltaic lighting system for highway", workshop on Towards a Better Environmental Future, Shaqra University, Saudi Arabia, PP. 20-25, 2014.

[9] N. Mutoh, M. Ohno and T. A. Inoue, "Method for MPPT control while searching for parameters corresponding to weather conditions for PV generation systems," IEEE Tran. on Industrial Electronics, Volume 53, No. 4, pp. 1055-1065, 2006.

[10] A. K. Abdelsalam, A. M. Massoud, S. Ahmed and P. N. Enjeti, "High-Performance adaptive perturb and observe MPPT technique for photovoltaic-based Micro grids," IEEE Trans. on Power Electronics, Volume 26, No. 4, pp. 1010-1021, 2011.

[11] Filippo Spertino, Jawad Ahmad, Alessandro Ciocia, Paolo Di Leo, Ali F. Murtaza, Marcello Chiaberge, "Capacitor charging method for I-V curve tracer and MPPT in photovoltaic systems" Solar Energy, Volume 119, Pages 461-473, September 2015.

[12] Boualem Bendib, Hocine Belmili, Fateh Krim," A survey of the most used MPPT methods: Conventional and advanced algorithms applied for photovoltaic systems", Renewable and Sustainable Energy Reviews, Volume 45, Pages 637-648, May 2015

[13] F. License, "Remote-control system of high efficiency and intelligent street lighting using a Zigbee network of devices and sensors," IEEE Trans. on Power Delivery, Volume 28, Issue 1, pp. 21-28, 2013.

[14] S.Sivagamasundari, P.Melba Mary, V.K.Velvizhi, " Maximum Power Point Tracking For Photovoltaic System by Perturb and Observe Method Using Buck Boost Converter", International Journal of Advanced Research in Electrical, Electronics and Instrumentation Engineering Vol. 2, Issue 6, 24-33, June 2013.

[15] J. Gu, F. Qing, L. Hua, X. Guo, L. Lv and Y. Yuan, "The design of one controlling circuit for solar lighting system", IEEE International Conference Information Science and Technology, pp. 1208 - 1211, China, 26-28 Mar 2011.

[16] C. Bhuvaneswari, R. Rajeswari and C. Kalaiarasan, "Analysis of solar energy based street light with auto tracking system", IJAREEIE, International Journal of Advanced Research in Electrical, Electronics and Instrumentation Engineering, Vol. 2, Issue 7, pp. 3422-3428, July 2013.

[17] Hegazy Rezk, Ali M. Eltamaly, "A comprehensive comparison of different MPPT techniques for photovoltaic systems”, Solar Energy, Volume 112, Pages 1-11, February 2015. 


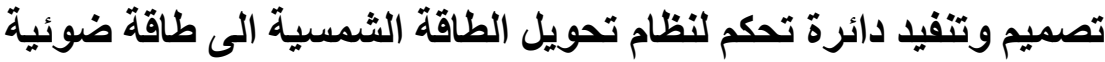

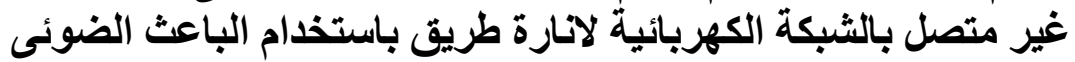

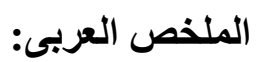

يهدف هدا البحث لتصميم وتنفيد دوائر التحكم لنظام تحويل الطاقة الثمسية الى طاقة ضوئية غير متصل بالشبكة الكهربائية لانارة طريق باستخدام الباعث الضونئى (photovoltaic)

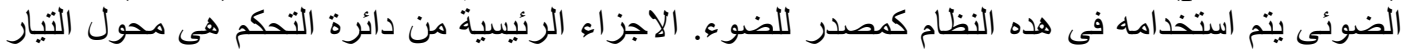

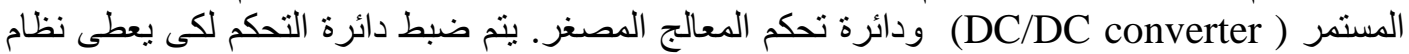

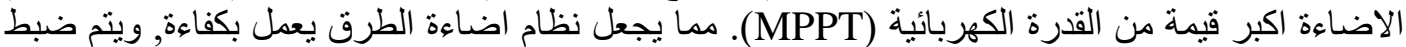

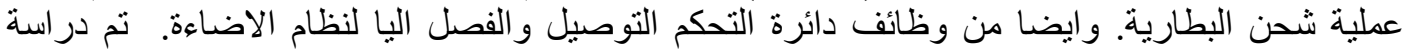

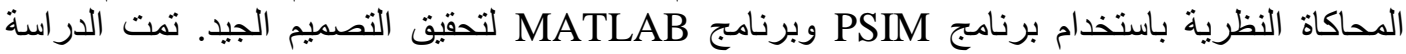

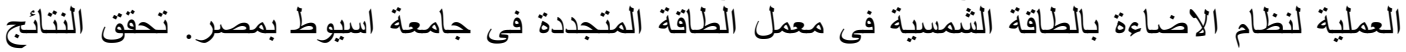

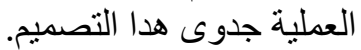

